\title{
INICIATIVAS DE USO POPULAR E REGULAÇÃO DEMOCRÁTICA DA BIODIVERSIDADE EM MEIO À CRISE AMBIENTAL PARA REDUÇÃO DA POBREZA E PROMOÇÃO DA QUALIDADE DE VIDA*
}

\author{
INITIATIVES OF PEOPLE'S USE AND DEMOCRATIC ADJUSTMENT OF \\ BIODIVERSITY FOR REDUCTION OF POVERTY AND PROMOTION OF QUALITY \\ OF LIFE IN THE ENVIRONMENTAL CRISIS
}

\begin{abstract}
Maria Cristina Vidotte Blanco Tárrega**
Adenevaldo Teles $\mathrm{Jr}^{* * *}$

\section{Resumo}

A biodiversidade tem valor econômico no mundo dominado pelo mercado. Hoje há a mercantilização da natureza e a privatização dos bens de uso comum, como a água, além de extratos vegetais. $\mathrm{O}$ uso da biodiversidade é do domínio das comunidades tradicionais. A proteção da biodiversidade por meio da garantia de direito às comunidades tradicionais e aos seus territórios e é uma forma de mitigar a pobreza e promover a justa distribuição de riquezas. O acesso popular à biodiversidade, apesar de aparentemente modesto, sugere uma nova relação com a economia e os recursos e patrimônios da Terra. É preciso cada vez mais exercer a governança ambiental na perspectiva de regular e promover uma gestão participativa da biodiversidade pelo reconhecimento dos sujeitos coletivos e das suas territorialidades.
\end{abstract}

Palavras Chave: Biodiversidade. Comunidades tradicionais. Conhecimentos tradicionais. Territorialidades. Gestão participativa da biodiversidade.

\begin{abstract}
The biodiversity has economic value in a world dominated by the market. Nowadays, there is the commercialization of the nature and the privatization of common use goods, like the water, and vegetable extracts, also. The use of the biodiversity is of the domain of the traditional communities. The protection of the biodiversity through the guarantee of rights to the traditional communities and its territories, is a way of alleviating poverty and promote a fair distribution of wealth. Even though it seems to be modest, the popular access to the biodiversity suggests a new relation with the economy, the resources and the assets of Earth. It's increasingly more needed to exert environmental governance from the perspective of regulating and promoting a new participative management of biodiversity, through the recognition of the collective subjects and their territorialities.
\end{abstract}

Keywords: Biodiversity. Traditional communities. Traditional knowledge. Territorialities. Participative management of the biodiversity.

\footnotetext{
* Trabalho produzido em pesquisa financiada pelo CNPq.

** Professora Titular na Universidade Federal de Goiás. Professor Adjunto na PUC Goiás e Universidade de Ribeirão Preto.

*** Graduando em Direito pela Pontifícia Universidade Católica do Estado de Goiás, Brasil. Pesquisa a efetividades dos acordos internacionais, Biodiversidade, Bioprospecção, Povos e Comunidades Tradicionais. E-mail: adenevaldo@outlook.com
} 


\section{Introdução}

Acredita-se na existência de um mundo que foi capaz de separar ser humano e natureza. Mundo esse dominado pelo mercado. A biodiversidade tem valor econômico na contemporaneidade. A popularização do acesso à biodiversidade e a proteção aos conhecimentos referentes a ela podem ajudar a superar carências econômicas de comunidades que apesar de detentoras de riquezas em bens imateriais padecem de necessidades outras de naturezas diversas. Essa superação deve se dar pela gestão democrática da biodiversidade.

Há um paradoxo- comunidades ricas em biodiversidade e conhecimentos sobre ela e pobres no que se refere aos bens originários dela, quando explorados pelo modelo econômico hegemônico ou pela economia globalizada. Esse sistema mercantilizou os bens e a vida. Transformou a natureza em mercadoria e hoje os defensores da economia verde argumentam que é necessário atribuir valor econômico aos bens da natureza para protegê-los.

O homem desenvolveu uma visão civilizatória antropocêntrica extremamente destrutiva. Por outro lado, a perspectiva universalizante e globalizante dos marcos regulatórios nacionais e internacionais, ao ignorar o contexto sociodiverso em que se diversifica a vida, a natureza, destitui as comunidades desses bens. Pior que isso, desterritorializam essa comunidades. Separam o homem da natureza e inventam direitos que a subjugam. Esses bens naturais passam à apropriação privada. Transformam-se em mercadorias e a sua gestão é capturada pelo mercado. As comunidades que conhecem e vivenciam tais bens não participam da gestão da apropriação mercadológica deles. Com isso, elas perdem os espaços da vida, de existência. Elas são desterradas. E o mercado rege o que era espaço das cosmogonias próprias.

A ganância dos agentes econômicos ignora as territorialidades e a multiversidade em que se produzem vida/conhecimento em mútua responsividade.

Os bens da vida, os biodiversos respondem aos conhecimentos multiversos dos muitos povos e muitas territorialidades. Pretender isolar a biodiversidade da sociodiversidade é ameaçar a vida. Depositar a gestão da biodiversidade nas mãos de 
representações construídas a partir de um modelo nortenho hegemônico é relegá-la ao mercado. É negar às comunidades geradoras da multiversidade a gestão da própria existência e do próprio destino - e aqui compreendida a diversidade da vida nos seus aspectos naturais e culturais, se é que se separam. E colocá-la em risco.

E isso afeta a humanidade. O fim da diversidade será o nosso fim.

\section{Mercantilização da Vida}

A abertura do Século XXI está sendo marcada pela crise civilizatória que torna tudo em mercadoria para o capital. A regulação dos mercados pelo capital tornou a vida mercantilizada em todos os sentidos. A patentealização dos seres humanos e do mundo(MATTELART, 2009, p.11-12) demonstram uma séria distorção dos valores ligados a vida e a promoção da sustentabilidade para a próximas gerações. A biodiversidade, título genérico dado a variabilidade de vida ${ }^{1}$, já sofre com a imposição de continuamente fornecer novos produtos ao mercado. Muitas dessas ações são em desrespeito as legislações internacionais que protegem os bens comuns para cercear sua privatização.

A perspectiva cientifica crítica assinala o atual contexto de mercantilização da biodiversidade, por meio da análise da economia verde. Tal observação reúne elementos suficientes para assinalar que os regimes jurídicos nacionais, e o modelo global, tentam valorar economicamente a natureza sob o argumento de que é a única forma de protegêla. Observa-se que tal argumento reflete interesses já previstos pelo processo histórico de produção e consumo, que desde a época das Grandes Navegações no Século XV, busca novos mercados para exploração comercial. A conjuntura atual remonta a ampliação e garantia de liberalidade ao mercado verde. A padronização de leis genéricas globais, beneficia negócios globalizados, em geral, indiferentes ao contexto social visando tão somente o capital.

A biopirataria, que é a apropriação indevida da natureza ou do conhecimento para fins de lucro e dominação, representa a nova face do colonialismo. Tão agressiva e dilapidadora quanto há 500 anos (DEBATE, 2012, p.137-144). A financeirização da natureza e o pagamento dos royaltes se tornaram mecanismos de exploração econômica 
dos recursos naturais por corporações transnacionais. Isso tem consequências espantosas para as comunidades tradicionais e os agricultores. $\mathrm{Na}$ Índia, como aponta Shiva, milhares de produtores cometeram suicídio nos últimos anos por conta da expropriação de seus territórios. No Brasil a Amazônia é vítima de empresas farmacêuticas que se apropriam de recursos naturais na fabricação de remédios, cosméticos, tinturas, monocultura, agrotóxicos entre outros. Esse contexto permite afirmar que o avanço tecnológico não melhorou em nada a promover a justa distribuição das riquezas.

Hoje se exalta o mercado como mecanismo racional de regulação de recursos naturais, e pretende-se, inclusive, que os problemas ecológicos surjam da ausência de racionalidade mercantil privada, como no caso do mal chamado "tragédia dos bens comunais". O ponto de vista ecologista nos leva a duvidar dos benefícios do mercado. O mercado impõe uma busca de ganhos, o que leva a um uso mais eficiente dos recursos, tal como de viu depois do crescimento dos preços do petróleo em 1973. Mas o mercado não garante que a economia se adeque ao ideal ecológico, já que o mercado sub-valoriza a vida, a natureza e as necessidades futuras. Não conta os prejuízos externos às transações mercantis.(ALLIER, 1992, p.2)

A Organização das Nações Unidas tem organizado Conferências Globais para discutir as questões climáticas e de acesso a biodiversidade há mais de duas décadas. Pode-se assinalar que a Conferência de Estocolmo em 1972 foi a primeira atitude mundial de organizar as relações do homem em relação ao meio ambiente. No histórico dessas conferências e encontros governamentais estratégicos, foram construídos diversos marcos regulatórios que conceituam e disciplinam medidas de cuidado com o meio ambiente. Se por um lado a tentativa de padronizar as legislações ambientais de centenas de países criou uma estrutura básica de preservação, por outro, tal medida proporcionou segurança jurídica aos negócios realizados por corporações transnacionais em busca de condições ideais para exploração industrial.

No contexto geopolítico, que divide os Países do Sul Global e do Norte Global, há uma tremenda dicotomia que centraliza as riquezas mundiais nos Países do Norte Global, mas hoje, dado o alto nível de industrialização desses países, as fontes de riqueza natural e as reservas energéticas restantes estão, em quase sua totalidade, nos 
Países do Sul Global. Tal contexto expressa a política colonialista que os países desenvolvidos têm exercido sobre os próprios bens naturais de seus territórios e o crescente interesse nas riquezas naturais dos países subdesenvolvidos.

Seja nos países ditos desenvolvidos onde a maior parte das riquezas mercantis estão concentradas, ou nos chamados países subdesenvolvidos, que abrigam grande parte dos recursos naturais ainda existentes, há uma séria disputa sobre a propriedade do patrimônio genético e consequentemente, sobre a biodiversidade. A ganância dos conglomerados econômicos ignora as peculiaridades dos territórios, assim como a história e tradição dos povos, em nome de um sistema que não necessariamente promove a vida e os seres humanos. A mudança precisa ocorrer nos estágios iniciais de contato com o patrimônio genético, na garantia de condições dignas de trabalho e contribuição a um sistema que não vise o lucro, mas a qualidade de vida de seus contribuintes para a coletividade.

A exposição da biodiversidade como patrimônio no mercado, alimenta um sistema insustentável de destruição dos recursos naturais, em nada contribuindo para a existência humana. O contato com a natureza e os conhecimentos da ecologia, demonstram o quanto os seres humanos são dependentes dos diferentes aspectos do Planeta Terra. É na natureza que encontramos expressões espirituais para a existência e matéria prima; a forma primária de produção de energia, e que hoje exerce diferentes reflexos sócio econômicos ligados a política de privatização e desregulação dos mercados. A atual estrutura de distribuição das riquezas do Mundo, reproduz uma desigualdade que precariza a qualidade de vida de todas as pessoas, tanto as que vivem nas cidades e no campo.

Entre outros pensadores, Bertha Becker, geógrafa e cientista, em entrevista concedida ao IPEA, afirma que a forma de resolver a crise socioambiental está na mudança da estrutura econômica. A presente crise socioambiental é resultado do sistema econômico vigente atualmente, para resolver os problemas de devastação ambiental e mercantilização da vida é necessário mudar o sistema capitalista que vivemos. Becker salienta que apesar de os países do Norte possuírem tecnologia, são os países do sul que detém as maiores reservas naturais. Isso assinala o contexto 
geopolítico contemporâneo que está voltado para a abertura de novos capitais nos países do Sul a partir da indefinida proposta de Economia Verde da ONU (BECKER, 2012).

A medida apontada para retardar esse processo de apropriação dos bens públicos em benefício de uma minoria que detém os meios de produção, é a inversão do ciclo de crescimento desigual que reproduz uma lógica de produção e consumo insustentáveis. É preciso garantir a autonomia dos povos sobre seus territórios, popularizando o acesso a biodiversidade como forma de mitigar a pobreza e mudar drasticamente o modelo de distribuição de renda em favor dos povos, de forma isonômica, tendo por fundamento paralisar a privatização da vida e perpetuar um padrão mínimo de qualidade de vida para todas as formas de vida, e também para as próximas gerações.

\section{Preservação das Territorialidades}

A ideia de preservação das territorialidades está intrinsecamente ligada ao conceito de território. Pensar em territorialidade é afastar o conceito moderno de território/estado/nação, para alcançar uma noção existencial em que o homem se liga ao espaço que ocupa, responsivamente.

Na noção de territorialidades, na perspectiva da proteção da biodiversidade, o conceito de território deriva essencialmente da identidade do grupo que ocupa o espaço físico, associada à auto-atribuição. Essa identidade se manifesta, com maior força, através da relação do homem em coletividade com a terra, que não é vista, apenas, como algo patrimonial. A terra, mais que o solo, constitui um dos mais importantes componentes da identidade desses sujeitos. É na relação que mantêm com a terra e com a natureza que se constrói a identidade dessas coletividades, haja vista que o modo de fazer, de viver e de criar desses sujeitos se articula, inteiramente, nesses espaços. $\mathrm{O}$ território constitui-se o espaço onde se articula a identidade cultural (em sua perspectiva mais ampla) e a relação desses sujeitos com a natureza. O conceito de território traz em si a simbologia necessária capaz de constituir elemento identitário fundamental, compreendendo as especificidades e as necessidades de cada comunidade e de cada povo, como componente inerente à própria vida dos mesmos. 
O território liga-se a identidade, tendo em vista que a construção do território cria uma identidade específica, e as ações dessa identidade constituem os elementos do território, por meio de processos coletivos dos sujeitos sociais, por meio da reciprocidade. A “territorialização também é construção, movimento, no tempo e no espaço. São relações entre os sujeitos e a natureza. Essa relação é registrada pela memória, individual ou coletiva, fruto de condição e saberes e conhecimentos" (MALCHER, 2006).

Território e identidade, neste conceito, tem relação de feedback; não se relacionam como sobreposição ou ação corretiva de um elemento sobre o outro. A recursividade ou os vínculos de ação recíproca entre esses elementos acarretam uma interação cujos resultados são de criação mútua, "no sentido paradoxal, mas verdadeiro, onde cada termo é, simultaneamente, causa e efeito do outro" (OST, 1995).

Foster explica a relação trabalho como um processo homem/ natureza em um processo de interação metabólica, como condição universal. Afirma que o trabalho movimenta as forças naturais a fim de apropriar os materiais da natureza, meio pelo qual ele atua na natureza.

\begin{abstract}
O trabalho é, antes de qualquer outra coisa, um processo entre o homem e a natureza, um processo pelo qual o homem, através das suas próprias ações, medeia, regula e controla o metabolismo entre ele e a natureza. Ele encara os materiais da natureza como uma força da natureza. Ele põe em movimento as forças naturais que pertencem ao seu próprio corpo, aos braços, pernas, cabeça e mãos, a fim de apropriar os materiais da natureza de uma força adaptada às suas próprias necessidades. Através desse movimento, ele atua sobre a natureza externa e a modifica, e assim simultaneamente altera a sua própria natureza... Ele [o processo do trabalho] é a condição universal da interação metabólica [Stoffwechsel] entre o homem e a natureza, a perpétua condição da existência humana imposta pela natureza. (FOSTER, 2005)
\end{abstract}

Se esses sujeitos representam a interação metabólica entre homem e natureza, a produção capitalista, especialmente relacionada à agricultura, por sua vez solapa as fontes originais de toda riqueza, o solo e o trabalhador

A produção capitalista congrega a população em grandes centros e faz com que a população urbana tenha uma preponderância sempre crescente. Isto tem duas consequências. Por um lado, ela concentra a força-motivo histórica da sociedade; por outro, ela perturba a 
interação metabólica entre o homem e a terra, isto é, impede a devolução ao solo dos seus elementos constituintes, consumidos pelo homem sob a forma do alimento e do vestuário; portanto, ela prejudica a operação da condição natural eterna para a fertilidade duradoura do solo... Mas, ao destruir as circunstâncias em torno desse metabolismo... ela impede a sua restauração sistemática como uma lei reguladora da produção social, e numa forma adequada ao pleno desenvolvimento da raça humana... [T] odo progresso na agricultura capitalista é um progresso da arte de roubar, não só do trabalhador, mas do solo; todo progresso no aumento da fertilidade do solo por um determinado tempo é um progresso em direção à ruína das fontes mais duradouras dessa fertilidade... A produção capitalista, portanto, só desenvolve a técnica e o grau de combinação do processo social da produção solapando simultaneamente as fontes originais de toda riqueza - o solo e o trabalhador. (FOSTER, 2005).

Com o limite das fronteiras do capital, em função do esgotamento da natureza, tendo em vista a incessante apropriação das terras e das águas, provocando a falha metabólica prevista por Marx, o direcionamento das frentes (MARTINS, 1997) passa aos territórios tradicionais, culturalmente preservados e que, ainda, não sofreram a grande transformação (POLANYI, 2000).

Preservar as territorialidades e garantir o acesso popular, apesar de aparentemente modesto, sugere uma nova relação com a economia e os recursos considerados patrimônios da Terra. O exercício da governança ambiental pelos governos do Mundo precisa seguir a perspectiva de regular e promover uma gestão participativa da biodiversidade e socialmente justa. A economia verde tem perspectivas frágeis sobre o desenvolvimento sustentável participativo e democrático, pois não coloca o Estado como órgão tutor do bem público, mas apenas regulador, o que descaracteriza a proteção dos bens comuns dos povos e atribui a estrutura pública apenas a tarefa de 'vender' e alienar os bens públicos.

\section{Considerações Finais}

Do mesmo modo que a indústria se modernizou ao longo da História para ampliar e conseguir processar qualquer recurso encontrado na natureza, é preciso desacelerar o crescimento e estabelecer metas de desenvolvimento realmente sustentáveis para os povos com foco nas suas territorialidades específicas. As crises econômicas e sociais nascem da comercialização das histórias humanas e dos recursos 
da Terra, perpetuando o estado de pobreza e miséria, porque são incapazes de oferecer um padrão de qualidade de vida satisfatória em nenhum lugar.

A grande competição em torno de matéria prima e do desenvolvimento de máquinas cada vez mais avançadas não promove qualquer melhoras efetivas nos padrões de desenvolvimento humano. O investimento nas coisas e não no ser humano movimenta um crescimento desigual que centraliza a riqueza dos povos e perpetua o estado de pobreza de outros milhares. O problema da pobreza está na relação com o meio ambiente, na extração, produção e distribuição das riquezas primárias. Grande parte das tecnologias de uso dos recursos naturais vem de conhecimentos geracionais que os povos acumularam com o passar dos anos para benefício mútuo entre as gerações, mas que foram incorporados às indústrias e suas práticas em prol de uma minoria.

A mudança para um novo mundo, exige de todos uma tomada de atitude para transformar o sistema político e econômico que vivemos. O Estado precisa ter sua força reguladora fortalecida, somente assim, será possível instituir a vontade coletiva sobre a força especuladora dos mercados verdes. Nas palavras de um diretor da École Nationale d'Administration, a famosa ENA, melhorar a produtividade do setor público constitui a melhor maneira de melhorar a produtividade sistêmica de toda a sociedade. ${ }^{2}$

O Direito enquanto área da ciência humana, precisa assegurar formas de proteção da vida a patamares socialmente justos de exploração e distribuição das riquezas naturais e condicionar seu uso ao benefício da coletividade a posteriori.

Está claro que a ideia de preservar a natureza agregando-lhe valor econômico capitaneada sobretudo por interesses de multinacionais e forças econômicas que influenciam os rumos políticos promove a injustiça social. Entretanto, não há qualquer sinal de que possa haver alguma mudança orientação. A mudança revolucionária precisa vir dos sujeitos de direito na sua condição cidadã identitária de seu próprio território em responisvidade, partindo de uma atitude política receptiva para crítica autônoma.

\section{Referências}


ALIER, Juan Matiner. Ecologismo dos Pobres. In: Revista WANI, Publicação mensal da Universidade Centroamericana (UCA) de Manágua, Nicaraguá, , n. 125, abril 1992, pág. 2-42 a 50 .

BECKER, Bertha - O que causa a perda da biodiversidade é a estrutura econômica que aí está. Revista Desafios do Desenvolvimento - SBS, Ano 9. Edição 72 - 15/06/2012 www.ipea.gov.br/desafios/index.php?option=com_content\&id $=2764 \% 3$ Acatid\%3D28\& $\underline{\text { Itemid }=23}$

DEBATE .Vandana Shiva e o Mundo Atual. Sustentabilidade em Debate - Brasília, v.3, n.1, pág. 137-144, jan/jun 2012.

FOSTER, John Bellamy. O conceito de natureza em Marx: materialismo e natureza. Rio de Janeiro: Civilização Brasileira, 2005.

MALCHER, Maria Albenize Farias. A Geografia da Territorialidade Quilombola na Microrregião de Tomé-açu: o caso da ARQUINEC - Associação das Comunidades Remanescentes de Quilombos Nova Esperança de Concórdia do Pará. Trabalho de Conclusão de Curso. Belém: CEFET, 2006.

MARTINS, José de Souza. Fronteira: a degradação do Outro nos confins do humano. São Paulo: Editora Hucitec, 1997.

MICHELOTTI, F.; RIBEIRO, B.; FLORÊNCIO, S. R. A Re-Existência Camponesa na Construção do Território do Sudeste Paraense (1995-2004). In: MONTEIRO, D.M.C; MONTEIRO, M. de A. (org.). Desafios na Amazônia: uma nova assistência técnica e extensão rural. Belém: UFPA/NAEA, 2006.

OLIVEIRA, Francisco de. A Economia da dependência imperfeita. Rio de Janeiro: Edições Graal, 1989.

OST, François. A natureza à margem da lei. A Ecologia à prova do Direito. Lisboa: Instituto Piaget, 1995.

POLANYI, Karl. A grande transformação: as origens de nossa época. Rio de Janeiro: Campus-Elsevier, 2000.

SARMENTO, Daniel. Territórios Quilombolas e Constituição: A ADI 3.239 e a Constitucionalidade do Decreto 4.887/03. Parecer emitido nos autos a ADI 3239/04. 2008. Disponível em: <http://ccr6.pgr.mpf.gov.br/documentos-e publicacoes/docs_artigos/Territorios_Quilombolas_e_Constituicao_Dr._Daniel_Sarmen to.pdf>. Acesso em: 06/07/2011.

\footnotetext{
${ }^{1} 2^{\circ}$ artigo da Convenção de Diversidade Biológica.

${ }^{2}$ L'écologie politique, remède à la crise du politique? Paru en français sous le titre. Traduction Ana-Maria Galano et Clara Linhart.
} 